\title{
Pattern of Dentoalveolar Abscess In A Nigerian Tertiary Hospital
}

\author{
Osadolor O.O* \\ Department of Child Dental Health, University of Nigeria Teaching Hospital, Ituku- ozalla, \\ Enugu State, Nigeria
}

Received: 30-05-2019 / Revised: 22-06-2019 / Accepted: 27-06-2019

\begin{abstract}
Background: Dental caries and its sequelae is a major public health problem. It affects both sexes, all races, all socioeconomic status and all age groups. One of the complications of untreated dental caries is dentoalveolar abscess.Objective: To determine the pattern of dentoalveolar abscess among patients attending a tertiary hospital in South-east Nigeria Methodology: A retrospective review of the hospital records of patients who attended and had oral clinical evaluation done in Preventive dentistry clinic of the Department of Preventive Dentistry, University of Nigeria Teaching Hospital, Enugu State, Nigeria from January 2013 to December 2015 was done. Results: A total of 113 patients were clinically evaluated and a diagnosis of dentoalveolar abscess was made ,75(66.4\%) were females,38(33.6\%) were males giving a female to male ratio of about 2:1 The age range of the patients was 17 to 93 years with a mean age of $39.3 \pm 18.3$ years. Dentoalveolar abscess was seen more in the 20-29 years age group, in mandibular first molars and was predominantly caused by dental caries. $\mathrm{P}$-value $=0.124$, P-value $=0.319$ Conclusion: Dental caries and its sequelae affects both sexes, all races, all socioeconomic status and all age groups. Untreated dental caries results in dentoalveolar abscess. Prevention of disease and suffering should be a primary goal of any society that hopes to provide a decent quality of life for its people.
\end{abstract}

Key words: Dentoalveolar abscess, pattern, abscess

\section{Introduction}

Dental caries and its sequelae is a major public health problem. It affects both sexes, all races, all socioeconomic status and all age groups [1-2]. Dental caries contribute to the global burden of oral diseases[3] and it restrict activities in school, at work and at home causing millions of school and work hours to be lost each year [4]. One of the complications of untreated dental caries is dentoalveolar abscess. Dentoalveolar abscess is a clinical condition associated with pus formation in the tooth and the surrounding alveolar bone.[5-6] It usually occurs secondary to dental caries or trauma[6-7]. Abscess formation occurs when bacteria and their toxic products enter the periapical tissues via the apical foramen and induce acute inflammation and pus formation.

\section{*Correspondence}

Osadolor 0.0

Department of Child Dental Health, University of Nigeria Teaching Hospital, Ituku- ozalla,Enugu State, Nigeria

E Mail: obcov2@gmail.com
The pathogenesis of dento-alveolar abscess is poly microbial in nature [8], comprising of various facultative anaerobes, such as the viridans group streptococci, the Streptococcus anginosus group, and strict anaerobes, especially anaerobic cocci, Prevotella and Fusobacterium species[6-8]. The treatment of a spreading, acute dentoalveolar abscess focus on pain control, antibiotics, surgical drainage and removal of the source of infection, which may include endodontic treatment or extraction of the tooth [9]. Majority of localized ones respond to surgical treatment/drainage, elimination of the source of infection and antibiotics. Previous studies reported dental caries as the main aetiological cause of dentoalveolar abscess [6,10-12], prevention of disease and suffering should be a primary goal of any society that hopes to provide a decent quality of life for its people [4]. Another study reported that females had more dentoalveolar abscess than males[11]. The occurrence of this condition vary from one individual or community to another; and depend on various factors among which are the oral care practices, the level of dental awareness and the behavior and attitude of the people in the community towards oral health. Poor oral health reflects social 
inequalities[13].The importance of good oral health among individuals cannot be overemphasized. Good oral health can promote good communication, good nutrition, and improve the overall quality of life. Poor oral health, on the other hand, can cause significant pain and infection, which may negatively affect social behavior or complicate medical conditions and their treatment [14]. Studies had shown that untreated dental caries is high in Nigeria.[15-16]. There are various studies on dentoalveolar abscess in Nigeria. The aim of this study is to determine the pattern of dentoalveolar abscess among patients attending a tertiary hospital in South-east Nigeria and compare findings with published reports from other parts of the country and other countries of the World. It would also contribute to the existing data on dentoalveolar abscess in Nigeria and the West African sub-region.

\section{Material and methods}

A retrospective review of the hospital records of patients who attended and had oral clinical evaluation done in Preventive dentistry clinic of the Department of Preventive Dentistry, University of Nigeria Teaching Hospital, Enugu State, Nigeria from January 2013 to December 2015 was done. University of Nigeria teaching hospital is a tertiary health facility serving many local government areas of Enugu State and neighbouring States. The demographic and clinical data, such as age, sex, aetiology, diagnosis and tooth/ teeth affected were retrieved from the patients' records and analyzed using SPSS version 20. Medical records with incomplete data were excluded. Ethical clearance for this study was sought from Ethical Committee of University of Nigeria Teaching Hospital, ( HREC, UNTH) Enugu, and obtained before commencement. Data were analysed using a computer software programme, Statistical Package for Social Sciences (SPSS) Version 20. P values $<0.05$ were accepted as being statistically significant.

\section{Results}

A total of 113 patients were clinically evaluated and a diagnosis of dentoalveolar abscess was made ,75(66.4\%) were females,38(33.6\%) were males giving a female to male ratio of about 2:1 The age range of the patients was 17 to 93 years with a mean age of 39.3 \pm 18.3 years as shown in Table 1. Dentoalveolar abscess was seen more in the 20-29 years age group, this was followed by the 30-39 years age group. The total number of teeth involved with dentoalveolar abscess was 127 , mandibular teeth $(68.5 \%)$ were more involved than maxillary teeth $(31.5 \%)$ as shown in Table 2. The mandibular first molar was affected the most. Dentoalveolar abscess was predominantly caused by dental caries and more on the right side of the dental arch. (Figure 1)

Table 1: socio-demographic characteristics of patients

\begin{tabular}{|c|c|c|}
\hline Variable & Number & Percent \\
\hline \multicolumn{3}{|l|}{ Gender } \\
\hline Male & 38 & 33.6 \\
\hline Female & 75 & 66.4 \\
\hline \multicolumn{3}{|c|}{ Age group(yrs) } \\
\hline $10-19$ & 14 & 12.4 \\
\hline $20-29$ & 32 & 28.3 \\
\hline 30-39 & 18 & 15.9 \\
\hline $40-49$ & 15 & \begin{tabular}{|l|}
13.3 \\
\end{tabular} \\
\hline $50-59$ & 13 & 11.5 \\
\hline $60-69$ & 14 & 12.4 \\
\hline 70-79 & 4 & 3.5 \\
\hline 80-89 & 2 & 1.8 \\
\hline $90-99$ & 1 & 0.9 \\
\hline & 113 & 100 \\
\hline
\end{tabular}


Table 2: Teeth involved in Dentoalveolar abscess

\begin{tabular}{|l|l|l|}
\hline Variable & Number & Percent \\
\hline Maxillary teeth & 40 & 31.5 \\
\hline Mandibular teeth & 87 & 68.5 \\
\hline & 127 & 100 \\
\hline P-value= 0.124 & & \\
\hline & & \\
\hline Central incisors & 7 & 5.5 \\
\hline Lateral incisors & 2 & 1.6 \\
\hline Canines & 2 & 1.6 \\
\hline First premolars & 10 & 7.9 \\
\hline Second premolars & 19 & 15.0 \\
\hline First molars & 51 & 40.2 \\
\hline Second molars & 19 & 15.0 \\
\hline Third molars & 17 & 13.4 \\
\hline & 127 & 100 \\
\hline P-value $=0.319$ & & \\
\hline
\end{tabular}

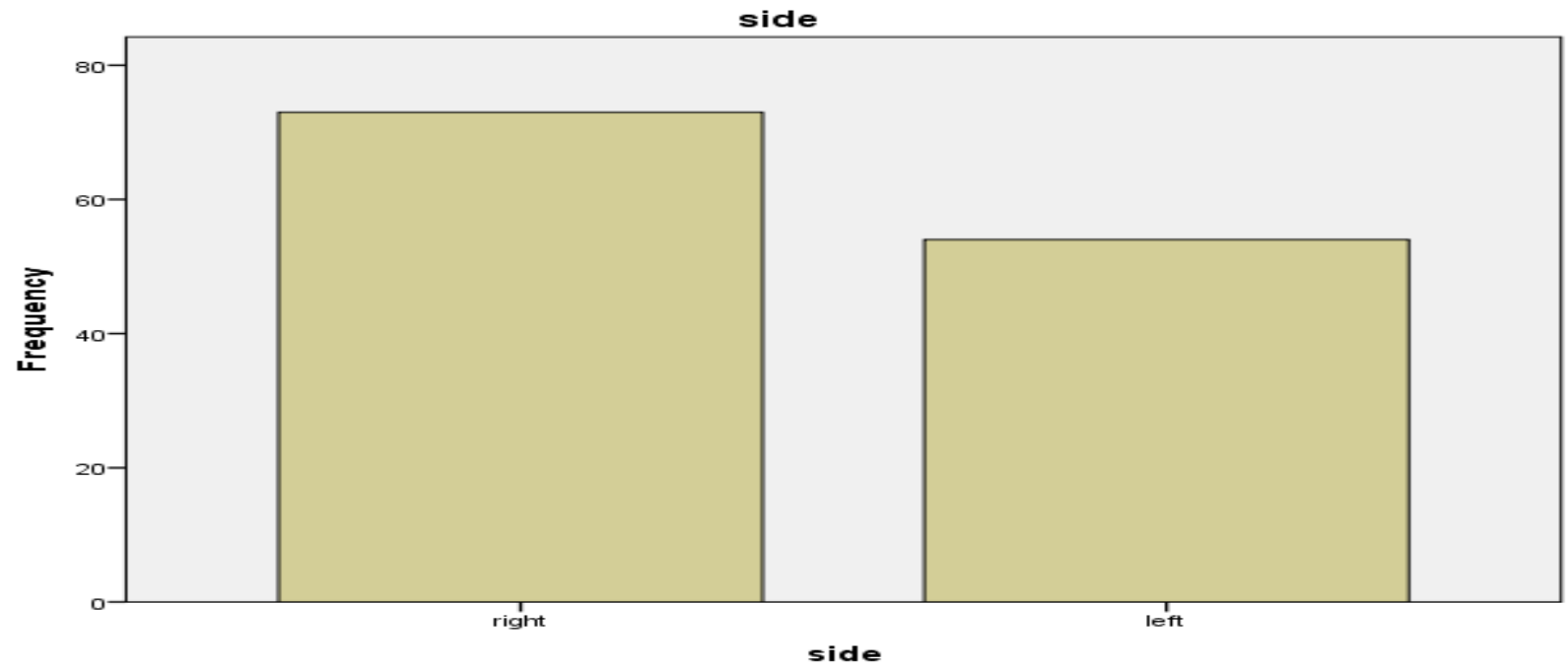

Fig 1 : Side of the dental arch where dentoalveolar abscess were seen.

\section{Discussion}

Healthy teeth and oral tissues are important for good quality of life. Females had been reported to be more concerned about their oral health [17-20] and they appear to be more motivated to utilize oral health care services. In this study, dentoalveolar abscess was seen more in females than males and was similar with previous study. [11] Oral diseases are major worldwide public health problems affecting a vast majority of adults [21]. Oral diseases are one of the most prevalent conditions in the world and are largely preventable. Dental caries and its sequelae affects both sexes, all races, all socioeconomic status and all age groups. Untreated dental caries results in dentoalveolar abscess. Another finding is that dentoalveolar abscess was predominantly caused by dental caries and was in agreement with previous studies [6,10-12] Prevention of disease and suffering should be a primary goal of any society that hopes to provide a decent quality of life for its people [4]. Dentoalveolar abscess was seen 
more in mandibular first molar and on the right side of the dental arch.

\section{Conclusion}

Dental caries and its sequelae affects both sexes, all races, all socioeconomic status and all age groups. Untreated dental caries results in dentoalveolar abscess. Prevention of disease and suffering should be a primary goal of any society that hopes to provide a decent quality of life for its people.

\section{References}

1. Prakash H, Sidhu SS Sundaram KR: Prevalence of Dental Caries among delhi school chidren. J Ind Dent Assoc.1999; 70:12-14.

2. Moses J, Rangeeth BN, Gurunathan D. Prevalence Of Dental Caries, Socio-Economic Status And Treatment Needs Among School Children. Journal of Clinical and Diagnostic Research. 2011; 5(1):146-151.

3. Braimoh OB, Umanah AU, Ilochonwu AN. Caries Distribution, Prevalence, and Treatment Needs among 12-15-Year-Old Secondary School Students in Port Harcourt, Rivers State, Nigeria. Journal of Dental Surgery; 2014:1-6.

4. Nakre PD, Harikiran AG. Effectiveness of oral health education programs: A systematic Review. Journal of International Society of Preventive and Community Dentistry. 2013;3(2):103-115.

5. Shweta S, Prakash SK. Dental abscess: A microbiological review. Dent Res J 2013; 10: 58591.

6. Onyejaka NK, Amobi EO. Dento-Alveolar Abscess in a Group of Nigerian Children. Int $\mathrm{J}$ Med Health Dev 2017; 22(2): 97-100.

7. Robertson D, Smith AJ. The microbiology of the acute dental abscess. Journal of Medical Microbiology.2009;58:155-162.

8. Nair PN. Pathogenesis of apical periodontitis and the causes of endodontic failures. Crit Rev Oral Biol Med 2004;15:348-81.

9. Seow WK. Diagnosis and management of unusual dental abscess in children. Aust Dent J 2003; 48: 156-68.

10. Azodo CC, Chukwumah NM, Ezeja EB. Dentoalveolar abscess among children attending a dental clinic in Nigeria. Odontostomatol Trop 2012; 35:41-6.

11. Osaghae IP. Dento-alveolar abscess: A case of poor dental visit and unawareness of dental treatment? Odontostomatol Trop 2014; 37: 39-45.

12. Al-malik M, Al-Sarheed M. Pattern of management of orofacial infection in children: a retrospective. Saudi J Biol Sci .2016; 24:13751379.

13. Osadolor OO, Osadolor AJ. Oral hygiene aids in a rural community in Nigeria. Int $\mathbf{J}$ Med Health Res.2019;5(5): 87-90.

14. Fiske J, Griffiths J, Jamieson R, Manger D. British Society for Disability and Oral Health Working Group. Guidelines for oral health care for longstay patients and residents. Gerodontology 2000;17:55-64.

15. Onyejaka NK, Amobi EO. Risk factors of early childhood caries among children in Enugu, Nigeria. Presqui Bras Odontopediatria Clin Integrada. 2016;16: 381-91

16. Folayan MO, Kolawole KA, Oziegbe EO, Oyedele T, Oshomoji OV, Chukwumah NM, Onyejaka N. Prevalence and early childhood caries risk indicators in preschool children in suburban Nigeria. BMC Oral Health 2015;15:72.

17. Omitola OG, Osagbemiro $T$, Akadiri OA. Spectrum of diseases and pattern of referral at the Oral diagnosis clinic of a tertiary dental center. Nig Dent J.2011; 19(2): 66-70

18. Augusto $\mathrm{CB}$, Ana HG, Cytia DE. Prevalence of endodontically treated teeth in a Brazilian Adult population. Braz. Dent. J. 2008; 19(4): 313-317.

19. Manga P. Charette A. The patterns and determinants of the utilization of dental care services in Canada. Canad $\mathbf{J}$ of Public Health.1986;77(1):119-123.

20. Osadolor OO, Egbonwonu F. Pattern of demand for endodontic treatment in a Nigerian teaching hospital. IJDMSR.2019;3(6):1-4.

21. Kahar P, Harvey IS, Tisone CA, Khanna D . Assessment of Oral Health Knowledge, Attitude, Utilization and Barriers toward Professional Dental Care among Adults in Central Rural India. OHDM -2016;15(2): 135-140.

Conflict of Interest: None

Source of Support: Nil 